Revista Complutense de Historia de América

ISSN: $1132-8312$

\title{
La hidroeléctrica de Tlaxcala, México. Una empresa estatal trascendiendo la época liberal y posrevolución. 1902-1943. Siguiendo impulsos, salvando obstáculos
}

Mariano Enrique Torres Bautista ${ }^{1}$

Recibido: 24 de agosto de 2018 / Aceptado: 23 de noviembre de 2019

Resumen. La significación de este caso estriba en su carácter de empresa creada desde antes de la revolución mexicana de 1910-17, por iniciativa estatal y con fondos públicos en un esfuerzo por modernizar una entidad caracterizada por su secular autonomía política dentro del contexto de la Nueva España y México.

Palabras clave: Empresa estatal; hidroeléctrica; época liberal; post revolución; Tlaxcala; siglo XX.

[en] The Hydroelectric Plant of Tlaxcala, Mexico. A State-Owned Company Transcending the Liberal and Post-Revolutionary Eras, 1902-1943. Following Instincts, Overcoming Obstacles

Abstract. The significance of this case lies in the company's creation before the Mexican revolution of 1910-17 by state initiative and with public funds, in an effort to modernize an entity characterized by its secular political autonomy within the context of New Spain and Mexico.

Keywords: State-owned company; Hydroelectric plant; Liberal era; Post-revolution; Tlaxcala; $20^{\text {th }}$ Century

Sumario. 1. Introducción. 2. Política, economía, compromiso y alianzas para crear una nueva fuente de energía. 3. La ansiada puesta en operación de la hidroeléctrica de Tlaxcala. 4. La hidroeléctrica en funciones después de las inquietudes políticas. 5. Conclusión. 6. Referencias bibliográficas.

Cómo citar: Torres Bautista, M. E. (2020) La hidroeléctrica de Tlaxcala, México. Una empresa estatal trascendiendo la época liberal y posrevolución. 1902-1943. Siguiendo impulsos, salvando obstáculos, en Revista Complutense de Historia de América 46, 177-195.

\section{Introducción}

Esta investigación tiene como objetivo central analizar los elementos que dieron origen a la primera empresa pública productora de electricidad en México y posiblemente una de las primeras creada precozmente por iniciativa estatal y con

\footnotetext{
1 Programa de Estudios Universitarios Comparados. Benemérita Universidad Autónoma de Puebla (México).

E-mail: mariano.torres@gmail.com
} 
fondos públicos en América Latina ${ }^{2}$. Entre las distintas interrogantes que sugiere son de destacar principalmente las siguientes: ¿Cuáles fueron los mecanismos de esta temprana iniciativa estatal en plena época de auge del liberalismo económico? ¿Cómo se manifiesta el espíritu modernizante de este gobierno que no parecía necesitar de obra pública para legitimarse? Ante estas cuestiones el objeto de este estudio tiene las siguientes características que le dan una fuerte significación. En primer lugar, el hecho de que la planta hidroeléctrica de Tlaxcala fue construida por iniciativa estatal en una época considerada por la historiografía de los estudios de la región como de crecimiento económico basado en políticas de Laissez-faire ${ }^{3}$. En segundo lugar, que no hubo una crisis de por medio, -como la de 1929 que inicia con el crack de la bolsa de valores en Nueva York- que diera origen a la intervención estatal como reguladora del panorama económico. En tercer lugar, es un caso de actitudes innovadoras impulsados por un gobierno estatal en busca de la modernización de servicios públicos como el alumbrado ante la nueva tecnología de la electricidad y sus aplicaciones, sin que mediara ninguna demanda ciudadana. En cuarto lugar, es una exploración sobre las motivaciones de esta iniciativa, toda vez que no se buscaba la legitimación del ejercicio del poder ante la población. Baste mencionar el hecho de que el Gobernador Próspero Cahuantzi no sólo detentó el poder más tiempo entre los gobernadores del dictador Porfirio Díaz, sino que siguió siendo un actor político cuatro años después de la caída de este régimen al dejar el cargo de gobernador fungiendo como "Jefe de las Fuerzas Armadas del Estado" hasta $1915^{4}$.

La investigación documental cuya información permitió descubrir este caso, requiere implementar tanto la metodología del análisis de texto, como enmarcarlo en el contexto sociocultural de Tlaxcala, una entidad con una notable identidad y personalidad política plurisecular. No obstante, en una época donde el país pasaba por una modernización acelerada, el impacto tecnológico que implicó la electrificación tuvo en esta entidad federativa como principal promotor al autócrata y no a las iniciativas empresariales privadas. La documentación clasificada correspondiente al periodo de surgimiento de esta empresa tampoco hace referencia a demandas ciudadanas. Resulta un caso muy significativo de empresa del Estado buscando la modernización a partir de la generación de la energía eléctrica, algo solo equiparable con lo que se verá en la Rusia posterior a la revolución de 1917. Así mismo, en textos dedicados a la cuestión del agua e industria de Tlaxcala este caso pasó completamente desapercibido, posiblemente por cuestiones cronológicas 5 .

2 El balance más completo nos muestra la participación estatal en empresas como respuesta a la crisis de 1930. Dávila L. de Guevara, 1996. Durante la construcción de los ferrocarriles mexicanos existió la modalidad de empresa estatal para algunos tramos: "Por administración directa del Estado, el Ferrocarril Nacional EsperanzaTehuacan, el Ferrocarril Nacional Puebla-San Sebastián Texmelucan [sic] -la población se llama San Martín Texmelucan- y el Ferrocarril Nacional de Tehuantepec" (disponible en: cf. catarina.udlap.mx/u_dl_a/tales/documentos/lic/capasso_g_ag/capitulo1.pdf). No obstante, como bien señala el autor, se trataba de unos tramos, no del total de la compañía, aunque es interesante ver que con esta intención modernizante compartida por el gobierno federal mexicano se dieron los primeros pasos en el camino de la inversión estatal en la economía mexicana.

Araya Ponchet, 2005; Ayala Mora, 2008: Halperín Donghi, 1998.

Rendón Garcini, 1993.

Juárez Flores, 2011: 25-48. 


\section{Política, economía, compromiso y alianzas para crear una nueva fuente de energía}

El 14 de abril de 1902 se firmó un convenio entre el gobierno del Estado y los vecinos del pueblo de Tlatempan estableciendo el derecho de estos a utilizar agua del río Zahuapan para riego de sus tierras a cambio de aceptar la apertura del canal destinado a conducir aguas para la planta propiedad del Gobierno del Estado ${ }^{6}$. Este hecho inicial quiere decir por una parte que, si bien no hubo iniciativas de particulares para el proceso de electrificación del sistema de alumbrado, siempre se tuvo cuidado de obtener la aquiescencia de las comunidades agrícolas circundantes para la disposición de los recursos en un permanente toma y daca con estos actores sociales colectivos. En los cuatro años siguientes no encontramos evidencia de la realización de negociaciones tendientes a obtener el concurso de inversionistas interesado en esta obra. Posiblemente por lo modesta que parecía esta obra a los ojos de los contratistas que sí se interesaron en obras de mayor envergadura en esta etapa de crecimiento económico e industrialización de la economía mexicana ${ }^{7}$. Será hasta fines de noviembre de 1906 que se dará el segundo y trascendental paso: la afanosa obra de canalización del río Zahuapan, por parte del gobierno del Estado también, para crear la caída artificial que propulsaría la nueva planta de energía hidroeléctrica ${ }^{8}$. Con la realización de esta obra el gobierno del Estado de Tlaxcala estuvo llevando a cabo también una acción de emprendimiento. No existe evidencia de que siquiera se lograse la participación de algún contratista o constructor para el trabajo de ingeniería civil implicado. Sobre este tipo de obra cabe destacar que se estaba utilizando un procedimiento ya conocido, similar al que se utilizó en muchos casos para extraer agua de los ríos aprovechable en riego agrícola. La diferencia en este caso es que ahora se destinaría para mover una turbina con la que luego se buscaba producir energía devolviendo el agua a la corriente algunos metros abajo.

Tuvieron que transcurrir tres años más para que en 1909 se manifestase el ejercicio del poder en tan novedosa labor de emprendimiento y política pública. Además de la cautela mostrada en la realización de la obra estos años sirvieron como periodo de gestión para continuar en la búsqueda del financiamiento sin quebranto de las finanzas públicas. Esta parsimonia es reveladora igualmente del control político que parecía no tener rivalidad significativa hasta ese momento.

La relación de poder entre el gobernador y los alcaldes de las ciudades implicadas permite apreciar lo ficticia que era la institución municipal como forma autonómica de gobierno. En el oficio que vemos a continuación se ve un mandato directo más que la convocatoria a una reunión de trabajo.

Dispone el C. Gobernador que, en unión de los demás miembros de esa P. Corporación, concurra Ud. a una junta que debe celebrarse en este Gobierno [...] con el

6 Dictamen relativo al uso agua en Hidroeléctrica de Tlaxcala. Ciudad de México, 12-III-1938. Archivo Histórico del Agua [México] (en adelante AHA), Sección Aguas Superficiales (en adelante AS), caja 2400, expediente 34090, hoja 43.

Connolly, 1997; Hart, 2011.

8 Oficio de Modesto Nava a Rafael Anzures, Alcalde de Tlaxcala, por perjuicios causados por la construcción del canal para conducir agua del río Zahuapan para la hidroeléctrica. Apetatitlán, Tlaxcala, México, 25-V-1906. Archivo Histórico del Estado de Tlaxcala [México] (en adelante AHET), Fondo Incorporado, Sección: Archivo Municipal, Serie: Ayuntamiento, caja 268, exp. 2, hoja 39. 
objeto de tratar el proyecto de alumbrado eléctrico en las poblaciones de Tlaxcala, Chiautempan y Apetatitlán, debiendo traer consigo los datos relativos a las cantidades que anualmente gasta [...] en el alumbrado público de esta cabecera ${ }^{9}$.

¿Parece exagerado decir que se trató de un mandato? Piénsese simplemente que no hubo la menor alusión a la agenda de trabajo de los otros alcaldes y los integrantes del cuerpo de regidores de los municipios. No obstante, el dominio político puesto en juego en el ejercicio anterior, no pudo sobreponerse a los requerimientos técnicos. La junta fue pospuesta a la espera de la recepción de los planos de las poblaciones a petición del Ingeniero Pedro Lira, asesor técnico del gobernador Próspero Cahuantzin.

A pesar de que las poblaciones implicadas contaban con el estatus de municipios, los oficios de envío y recepción de los planos muestran en los hechos como estas se encontraban jerarquizadas de manera piramidal, en un esquema que distaba mucho de la cultura política liberal que venía inspirándose desde las Cortes de Cádiz ${ }^{10}$. A la figura del gobernador Prospero Cahuantzi seguía en importancia su Secretario de Gobierno, a este el Presidente Municipal de la ciudad capital de Tlaxcala, mismo al que le seguían los presidentes municipales de Santa Ana Chiautempan y San Pablo Apetatitlán. Este conjunto de funcionarios y poblaciones conformaban así un núcleo de poder, basadas en su posición dentro de la zona central del Estado, toda vez que su importancia económica no correspondía con las estructuras productivas, no tenían los elementos que las hiciesen idóneas para el desarrollo de las actividades más significativas del momento. Baste señalar al respecto por ejemplo, que la zona agrícola más fértil y rica por ser zona de humedales se encontraba en el suroeste ${ }^{11}$, mientras que la mayor concentración de industrias estaba en el sur, también en la parte colindante con el Estado de Puebla ${ }^{12}$.

La carta del 30 de noviembre de 1905 por parte del gestor y asesor técnico Diego Kennedy al gobernador Cahuantzi, evidencia los esfuerzos que se siguieron desplegando para formar una compañía o sociedad anónima por acciones al más puro estilo liberal ${ }^{13}$. Esto significa que la política de modernización de servicios públicos como el alumbrado iba de la mano de la ideología liberal predominante, que los esfuerzos iniciales por atraer dinero de inversionistas particulares se llevaron a cabo aunque no se lograron concretar.

El objetivo de modernización buscaba también sustituir las bombillas de mica de corta durabilidad que, además de consumir gasolina comprada en la ciudad de México, implicaban gastos de transporte, etc., por 34.31 pesos mensualmente a las finanzas del Ayuntamiento de la ciudad de Tlaxcala ${ }^{14}$. Así mismo, este sistema de alumbrado generaban otros gastos, tal y como se desglosa en el recibo de la foto que permite apreciar incluso impuestos implicados, además de los hermosos dispositi-

9 Citatorio del Alcalde Rafael Anzurez a los Regidores del Patriótico Ayuntamiento de Tlaxcala, México. Tlaxcala, México, 10-X-1905. AHET, Oficios varios, caja 260, exp. 4.

10 Guerra, 2009.

11 Rendón Garcini, 1993: 99.

12 González Navarro, 1970: 221.

13 Carta de Diego Kennedy al Gobernador de Tlaxcala, Coronel Próspero Cahuantzin, relativa al alumbrado eléctrico de esta ciudad y al Banco Central Mexicano, San Juan Atoyac, Oficios varios. Tlaxcala, México, 30-XI1905. AHET, caja 260, exp. 4, hoja 9.

14 Gastos del Alumbrado público en el mes de mayo de 1906. Tlaxcala, México. 31-V-1906. AHET, caja 267, exp. 1 , Hoja 51 vuelta. 
vos utilizados en esos años. El hecho mismo de contar con servicio de alumbrado es indicativo del ideal de modernidad urbana que de esta manera había realizado el gobierno del Estado, una entidad que también había hecho exitosos progresos en el establecimiento y desarrollo de una industria textil mecanizada, a pesar de no contar con una clase empresarial industrial local toda vez que la mayor parte de propietarios de las fábricas residían en la ciudad de Puebla ${ }^{15}$.

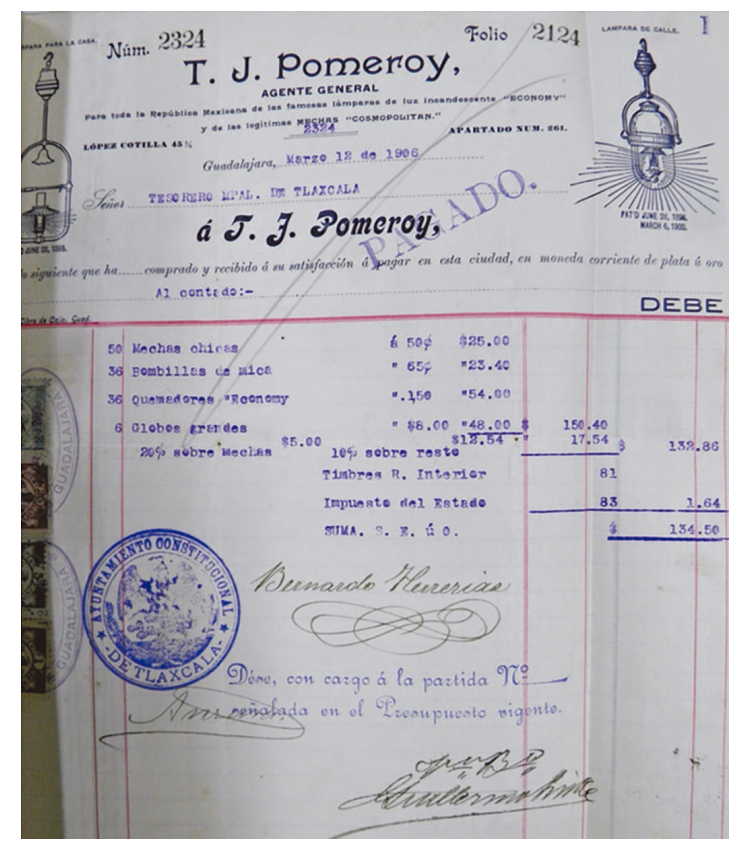

Figura 1. Recibo con grabado de bombilla ${ }^{16}$.

En enero de 1906 se dieron a conocer las bases para arrendar la caída artificial en proceso de construcción. Esta convocatoria demuestra por una parte que de manera gradual se venía dando la realización de la obra civil con los materiales y técnicas constructivas conocidos. Estos trabajos implicaron el uso intensivo de la mano de obra de alarifes y materiales de la región para su construcción. Sin embargo, contar al mismo tiempo con el equipo requerido para la planta hidroeléctrica implicaba el uso de dispositivos tecnológicos conocidos ya en el país pero necesariamente importados. Hasta ese momento se disponía solamente de la cotización realizada por la casa Schöndube \& Neugebau de la ciudad de México. Las características del equipo comprendían una potencia de entre 150 y 190 caballos de fuerza en una caída de 8 metros provenientes de 1,900 litros de agua por segundo. Estas dimensiones eran realmente modestas comparadas con los 32, 000 litros de agua en una caída de 56 metros con los que contaba la planta de Necaxa en el vecino Estado de Puebla, cons-

Alba González, 1991.

16 Fuente: Justificantes de los Números 1 al 5 para alumbrado público. Tlaxcala, México. 12-III-1906. AHET, Sec. Archivo Municipal, Serie Ayuntamiento, caja 267, exp. 1. 
truida de manera paralela ${ }^{17}$. Las bases para el pretendido arrendamiento establecían el compromiso de instalar turbinas, cableado hacia el centro de la ciudad de Tlaxcala y que:

VII. El arrendatario tendrá obligación de terminar las instalaciones [...] a los seis meses de firmarse el contrato [...] VIII. [...] proporcionará al Ayuntamiento el número de focos (de 96 bujías) de arco [...] para el alumbrado público, y los incandescentes (de 16 bujías) indispensables para las oficinas del Gobierno ${ }^{18}$.

Es evidente que los beneficios del nuevo sistema de alumbrado estuvieron pensados para el disfrute de la población en calles principales y espacios de uso común; pero también el que hasta el último momento se desplegaron esfuerzos para obtener el concurso de la inversión privada, una tónica que trató de seguir en todo momento las palabras de Joaquín Casasús, quien fuera Embajador de México en los Estados Unidos en 1905:

México ha de menester de capitales para fecundar sus riquezas, y como el desarrollo de la industria está limitado por el capital que a ella se consagra, ha menester, si quiere prosperar y enriquecerse, consagrar cada día mayores capitales para la explotación de sus riquezas ${ }^{19}$.

Al tiempo que continuaba la intención de obtener el concurso de la inversión particular, los recursos necesarios para la parte constructiva de la obra perseguida empezaron a trasvasarse del gobierno del Estado de Tlaxcala al Ayuntamiento de la ciudad del mismo nombre. La cuestión del alumbrado se reflejó dentro de las finanzas municipales en forma de "subvención". La intervención económica estatal había dado de esta forma otros pasos en esta trayectoria como deja ver este ejemplo:

Tesorería Municipal

Estado Corte de Caja que practicó esta oficina por los ingresos y egresos habidos en ella en el mes de la fecha.

INGRESOS

Existencia del mes anterior

Producto por rezago de todos ramos

Producto por réditos de capitales

Producto por ventas de terrenos

Producto por venta de pedreras o canteras

Producto por ventas de cuartos

Producto por ventas de mercedes de agua

Producto por renta de la Plaza de toros

Producto del Rastro.

Producto de las tocinerías
Municipal

$.37,43$

132,50

$.420,50$

. .00

. .00

$.35,50$

$.66,25$

. .00

$.63,06$

.73,00
Federal

00

1,50

00

00

00

00

00

00

15,76

18,27

\footnotetext{
17 Díaz Lombardo. 1907: 236.

18 Contrato entre el Ayuntamiento de Tlaxcala con el Banco Central Mexicano. Distrito Federal, México, 1-I-1906. AHET, Sec. Archivo Municipal, Serie Ayuntamiento, caja 260, Exp. 4.

19 Canudas, 2005: 418.
} 
Producto del Mercado público $.65,72$

Producto de aparadores o alacenas .............................................00

Producto del Fiel Contraste......................................................................

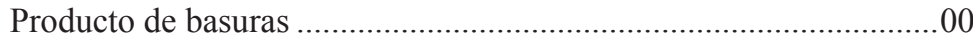

Producto por la manutención de presos .........................................6,00

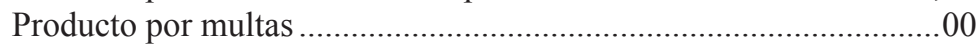

Producto por expendios de licores .....................................................00

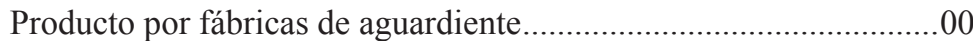

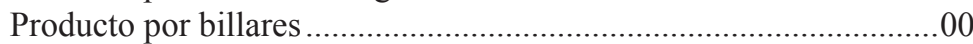

Producto por casas de empeño ………………………………….........

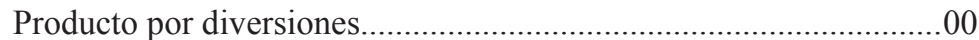

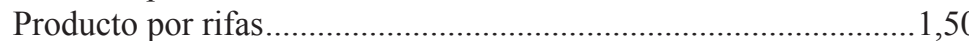

$10 \%$ Producto por terrenos $.0,50$

Producto por derecho de piso sobre carros, carretas y carretillas de transporte. $. .0,80$

Producto por derecho de patente $.42,03$

Subvención del Gobierno del Estado. $.200,00$

Suma $1,144,29$

Vo. Bo. Rafael Anzures Interventor Guillermo Zintle

(Rúbricas)

Tlaxcala, 31 de marzo de $1906^{20}$.

Es interesante observar que el nuevo rubro inserto, relativo a la "subvención del Gobierno del Estado" comenzó a anotarse de manera manuscrita en los formatos utilizados e impresos desde tiempo atrás. Esto significa que se había agregado recientemente, a principio del ejercicio fiscal de ese año. De esta manera podemos apreciar un reflejo del peso que iba adquiriendo el poder público sobre la vida de la ciudad, ahora sobre la cultura material, a través de esta nueva tarea asumida. También es conveniente recordar que, después de la caída del II Imperio Mexicano (1867), el ala liberal de la élite política mexicana había logrado el grado de legitimación política por el que se había librado aquella lucha. Pero igualmente podemos apreciar otro hecho: la correspondiente salud financiera que posibilitó el empezar a realizar esta subvención de manera regular. Esta coyuntura coincide no solo con el calendario de la agitada vida política mexicana durante el siglo XIX, sino que formó parte de una tendencia general al fortalecimiento institucional en la América Latina entre 1870 y 1929 , como se aprecia en la historiografía especializada ${ }^{21}$.

Los acontecimientos determinantes en la formación de la empresa energética estatal se dieron entonces siguiendo una rápida sucesión. La cuestión financiera era uno de los principales retos en esta voluntad de emprendimiento para la cual no bastaba con llevar al terreno el imaginario modernizador ni la determinación política. La cuestión financiera era ineludible. Lo interesante del caso que nos ocupa es que no se venía dando el tránsito hacia la modernización tecnológica, también se aprecia en el entorno de los mecanismos financieros, un afortunado paso de las prácticas tradicionales hacia aquellas desarrolladas en esta era del capitalismo de principios del siglo

20 Fuente: Tesorería Municipal. Estado-Corte de Caja que practicó esta oficina por los ingresos y egresos habidos en ella en el mes de la fecha. Tlaxcala, México. 31-III-1906. AHET, caja 267, exp. 1, Sin número de Hoja.

21 Bértola - Ocampo, 2013: cap. III. 
XX. Es por eso que el 28 de mayo de 1906 se elaboró una lista de los créditos que el Ayuntamiento de Tlaxcala había venido otorgando a individuos y a colectividades. Estos llegaron a formar un modesto pero significativo conjunto de 11 préstamos que alcanzaron un monto de $86,204.50$ pesos, mismos que al 6\% anual producían réditos por 5,172.24 pesos $^{22}$. La lista que cubría las fechas que iban del 26 de septiembre de 1856 al 7 del mismo mes de 1905. Aunque se trató de un largo periodo de casi medio siglo, sólo se incluía en la misma a 9 particulares y 3 comunidades o actores colectivos de antiguo régimen funcionando bajo la figura de "Sociedad agrícola" o "vecinos de [...]". Los montos de estas cifras también contienen elementos significativos respecto al ejercicio y equilibrio de poderes. Primero, el hecho de que, ante la implementación de las leyes liberales de desamortización, que entre otras cosas establecieron la extinción de bienes de corporaciones ${ }^{23}$, en Tlaxcala fue el gobierno del Estado quien sustituyó el papel de la Iglesia Católica como institución crediticia de antiguo régimen. Esto quiere decir que este gobierno desde 1856 había incursionado también en la realización de operaciones como empresario en el incipiente ramo financiero, cuestión relevante de la que subsiste la documentación pertinente, sin embargo, fuera de los objetivos de este ensayo. Así mismo, esta detallada lista así recabada nos muestra el hecho de que aunque a pesar de que el monto de dichos préstamos equivalía prácticamente al costo del equipamiento de la hidroeléctrica, -como veremos enseguida- la naturaleza de estos préstamos no hacía posible la recuperación inmediata de esos créditos. Esta información también hace evidente el hecho de que la suma de los réditos percibidos tampoco daba la posibilidad de cubrir el costo del equipamiento necesario para el salto tecnológico en el sector energético hidroeléctrico dedicado al alumbrado público.

E1 25 de mayo de 1906 se dio otro avance en el camino que cada vez llevaba más y más a la creación de un ente completamente estatal. En esa fecha se hizo público el acuerdo por el que el Ayuntamiento autorizaba a Rafael Anzures, Alcalde de Tlaxcala, para "celebrar con el Banco Central Mexicano un contrato de empréstito por la cantidad de ochenta mil pesos [... $]^{\prime 24}$. Este paso fue el decisivo cruce del umbral que, ante el desinterés de inversionistas privados por participar en la construcción de esta hidroeléctrica, obligó al Estado de Tlaxcala a convertirse en empresario de la producción de electricidad en los albores del siglo XX. Cabe destacar que el problema no había sido el monto, la cantidad necesaria no era equiparable a las faraónicas inversiones que requirió la construcción del complejo hidroeléctrico de Necaxa ${ }^{25}$.

También es importante subrayar entre los fenómenos que permite analizar este caso el hecho de que no fue una coyuntura de crisis generalizada la causa central que fuese empujando hacia la intervención del Estado en la economía, tal y como es conocido el proceso dentro de la historia económica mundial a partir del crack de la bolsa de valores neoyorkina ${ }^{26}$. Dentro del marco de análisis principal, Bértola y Ocampo plantean igualmente como característica del periodo previo a la gran depresión mencionada un interesante contexto: la idea de que es una de las épocas de globalización económica para el subcontinente. Claro está, esta perspectiva de

\footnotetext{
22 Copia certificada de la minuta de contrato celebrado por el Ayuntamiento de la ciudad de Tlaxcala con el Banco Central Mexicano S. A. Distrito Federal. México, 28-V-1906. AHET, caja 268, exp. 2. junio de 1906. Secretaría de Hacienda y Crédito Público, 1880: LXXXIX. 
acceso a nuevas tecnologías e inserción en mercados, no substituye al planteamiento de Halperin Donghi, el clásico de la historia general latinoamericana que en el título de su largo capítulo expresa la pauta que caracteriza a este medio siglo de "Madurez del orden neocolonial" 27 . En el mismo sentido, es más conocida la historia de que dicha conexión a escala mundial tuvo como fundamentos su conocido desarrollo en base a las exportaciones de materias primas. Así mismo, nos parece importante el destacar también dentro de la perspectiva de Bértola y Ocampo su cuarto capítulo donde señala como pauta de los "procesos de industrialización dirigidos por los gobiernos" evitando y superando como perspectiva analítica reciclar el antiguo término de "sustitución de importaciones", proceso especialmente característico de las mayores economías de la región: Argentina, Brasil y México ${ }^{28}$. De esta manera, vemos que a nivel continental la mano correccional y hasta interventora del Estado sobre las distorsiones inducidas por una economía de libre mercado y que de manera generalizada se vino dando más bien a partir de los efectos cíclicos de la economía internacional. Este transfondo continental sin lugar a dudas hace más singulares las acciones emprendidas dentro de nuestro caso de estudio, toda vez que aquí vemos más que los esfuerzos por llevar a cabo la corrección de algunos de los efectos económicos adversos, la puesta en marcha de inversión estatal de forma directa y con una temporalidad de poco menos de un cuarto de siglo antes; es decir, de manera significativamente precoz en el contexto no solo mexicano sino latinoamericano.

Detrás de la relevancia de este hecho singular estuvo desde luego la voluntad del Gobernador del Estado de Tlaxcala -la entidad federativa más pequeña de la república mexicana- de modernizar, de equiparar en niveles de servicios a la ciudad capital de la misma con otras ciudades del país. Aquí tenemos entonces las acciones de un gobierno que no cabe solamente en los parámetros más utilizados de "paternalista", "dictatorial", "patrimonialista", etc. Desde el punto de vista metodológico es más adecuado hacer la exploración del desarrollo de una empresa estatal ciertamente, pero sin olvidar que fue administrada dentro de un esquema de capitalismo no tanto por la búsqueda de utilidades a partir de su operación sino más bien por la manera en que tuvo que enlazarse a los esquemas de financiamiento para acceder a los proveedores de la tecnología necesaria. Lo interesante del caso es igualmente la parte híbrida enlazada con comunidades agrarias para acceder a los espacios necesarios durante el proceso constructivo de las instalaciones. De la mayor parte de estas operaciones existen tanto vestigios documentales como físicos como son el canal, las compuertas y el vaso de reserva hidráulica que fue necesario construir como veremos más adelante.

Igualmente, es importante destacar que al realizar la firma del contrato con el Banco Central no se hipotecó ningún bien ni recurso extraordinario, por el contrario, el préstamo con la entidad financiera privada se logró mediante un inteligente arreglo en dicho instrumento que estableció como garantía del empréstito a la propia maquinaria adquirida para instalar la planta hidroeléctrica. Aunque el espacio de análisis de este caso no lo permite, no podemos dejar de lado la conexión entre, un esquema de poder basado en mecanismos tradicionales como los vínculos personales por una parte-por ejemplo compromisos entre la autoridad central y actores colectivos como pueblos y comunidades campesinas- y por la otra con entidades privadas funcionan-

\footnotetext{
Halperin Donghi, 2005: 280-357.

28 Bértola-Ocampo, 2013.
} 
do plenamente en la lógica capitalistas de la época como la casa comercial Schöndube \& Neugebauer, y financieras como el Banco Central Mexicano. Tenemos así un desempeño pragmático que oscilaba entre tradición y modernidad para conseguir los objetivos de transformación, actitudes que no caben simplemente en un esquema de racionalidad económica puramente capitalista ${ }^{29}$.

\section{La ansiada puesta en operación de la hidroeléctrica de Tlaxcala}

La acuciosa documentación conservada en el Archivo Histórico del Estado de Tlaxcala aunque no tiene ninguna sección dedicada exclusivamente al desempeño de esta planta hidroeléctrica, no obstante, permite percibir otras facetas de este gobierno emprendedor y modernizante. Por ejemplo, el hecho de que el mismo personal político pasaba de un cargo a otro bajo la tutela del gobernador Cahuantzi. Descubrimos que, además de la novedad del artificio tecnológico que atrajo el interés del gobierno estatal, al entrar en el trato bancario privado para llevar a cabo los consabidos pagos emitidos al representante de la compañía AEG de Berlín: la casa Schöndube \& Neugebauer de la ciudad de México, los abonos realizados no se distinguieron justamente por la puntualidad en su aplicación. Los retrasos se debieron posiblemente al esfuerzo económico realizado para seguir cubriendo simultáneamente el costo del alumbrado en base al uso de combustible fósil mientras se lograba echar a andar la producción del fluido eléctrico que terminó sustituyéndola.

Una vez que se logró contar con el canal, la turbina y maquinaria para la planta, hubo que hacer frente a otro problema técnico para el funcionamiento eficiente del equipo adquirido: la exigua e irregular afluencia proporcionada por la obra no permitía la correcta operación y consecuentemente la producción del fluido eléctrico. La solución propuesta requería un nuevo reto tanto constructivo como financiero: contar con un reservorio para acumular el agua del canal para luego vertirse de manera constante, especialmente durante los horarios nocturnos en que era requerido el suministro de la energía eléctrica. Evidentemente, los de por sí limitados recursos extraordinarios, asignados como subvención estatal, no tenían contemplado este nuevo esfuerzo financiero, por lo que tuvo que entrar en ejercicio una vez más el concurso de la autoridad pero ahora haciendo uso de mano de obra gratuita de los pueblos campesinos de las municipalidades implicadas. Este ordenó la realización de "faenas", mecanismo mejor conocido por el vocablo náhuatl tequitl, equivalente a tributo o trabajo comunitario de los vecinos de las poblaciones, fórmula de corte tradicional cuyas raíces parten desde los tiempos previos a la colonización española ${ }^{30}$. La documentación disponible no permitió apreciar la negociación que necesariamente tuvo que darse con la comunidad de San Pablo Apetatitlán, de donde se tomó el terreno necesario para la construcción del reservorio, mismo que, dicho sea de paso, sigue existiendo actualmente pero como estanque de recreo en torno al cual se construyó un zoológico y permite ahora la conservación de algunas especies acuáticas, también de propiedad estatal. La realización de esta obra complementaria deja pensar, por una parte, en la eficacia del poder del gobernador Cahuantzin. Por otra, ante la difusión que presumiblemente había tenido lugar el desarrollo tecnológico entre la

Elster, 2002: 343-395.

30 Warman, 2003: 235-236; ref. en Chávez Peón - San Giacomo. 
población, su respuesta fue colaborar aunque aún no había comenzado a percibir los beneficios del artificio, y que no obstante también accedió a ceder el terreno necesario para el reservorio en una zona densamente poblada desde tiempo atrás ${ }^{31}$.

Algo cuestionable hoy en día pero aparentemente aceptable en estos momentos, es el hecho de que en la obra de construcción del canal se empleasen carretas para transporte del material propiedad del Gobernador y del Tesorero del Estado. ${ }^{32}$ Igualmente incuestionable fue la decisión del ejecutivo tlaxcalteca de ordenar la remoción de lámparas de arco de la población de Santa Ana Chiautempan [...] "y algún otro material que solicite para una instalación en el pueblo de Ixtulco [...]"33. Esto significa que al proyecto de modernización del alumbrado de la capital del Estado, se sumó la decisión de mejorar con instalaciones eléctricas el servicio público en la población de origen del autócrata local. Este dato nos permite saber que fue a partir del año de 1907 cuando comenzó a operar en forma la planta hidroeléctrica estatal de Tlaxcala, con todo lo significativo que tiene esta empresa y su puesta en operación.

La aplicación de dinero público para la obra emprendida se dio hasta el último momento. Todos los recursos a la mano fueron empleados. Esto es lo que dejan ver los recibos como el del 4 de julio por el que Vicente Chumacero daba por saldada la hipoteca que reconocía a favor del Ayuntamiento de su rancho Las Ánimas, "quedando estos fondos consignados a la cuenta de la instalación de la planta eléctrica de esta ciudad" ${ }^{34}$. Esta y otras hipotecas concedidas por el gobierno del Estado a particulares, revelan un desempeño sui generis como banca comercial popular, una vez que las leyes de desamortización suprimieron esta función que desde el periodo virreinal venía desempeñando la Iglesia Católica.

En este sentido, en agosto de este año se anotaba:

El ciudadano Gobernador del Estado ha tenido a bien conceder al H. Ayuntamiento [...] la cantidad de UN MIL OCHOCIENTOS PESOS, completando la de TREINTA MIL PESOS que en calidad de préstamo del erario del mismo Estado ha obtenido para la terminación de las obras emprendidas a fin de establecer el alumbrado eléctrico de esta ciudad ${ }^{35}$.

Estos desembolsos van más allá de movimientos financieros, muestran una estructura de poder donde las figuras del gobierno estatal y el gobierno municipal aparecen solo como fachada institucional de un poder basado en la relación pirami-

31 Censo General de la República Mexicana. México, 20-X-1895. Instituto Nacional de Estadística Geografía e Informática. Sección Censos. Disponible en: www.inegi.org.mx

32 Recibo del Coronel Próspero Cahuantzin por $\$ 100.00$, con cargo al fondo destinado para la obra del río Zahuapan. Tlaxcala, México, 3-VI-1907. AHET, Sec. Archivo Municipal, Serie Ayuntamiento, caja 275 sin número de hoja.

33 Oficio del Coronel Próspero Cahuantzin al alcalde de Santa Ana Chiauteman, Tlaxcala, México, 10 de enero 1908. AHET, Sec. Archivo Municipal, Serie Ayuntamiento, caja 278, exp. 2, Sin número de hoja.

34 Oficio del Alcalde de la ciudad de Tlaxcala, Rafael Anzures al C. Tesorero de este Ayuntamiento, por hipoteca del rancho de las Ánimas por hipoteca redimida. Tlaxcala, México, 4-VII-1907. AHET, Sec. Archivo Municipal, Serie Ayuntamiento, caja 275, exp. 1.

35 Oficio del Alcalde de la ciudad de Tlaxcala, Rafael Anzures al C. Tesorero de este Ayuntamiento, por préstamo recibido del C Gobernador, Próspero Cahuatzin. Tlaxcala, México, 7-VIII-1907. AHET, Sec. Archivo Municipal, Serie Ayuntamiento, caja 275, exp. 1, sin pág. 
dal y de vínculos personales tal y como desveló François X. Guerra a propósito del régimen existente en el país antes de la revolución mexicana de $1910^{36}$.

\section{La hidroeléctrica en funciones después de las inquietudes políticas}

Una vez que se habían extinguido las flamas del enojo popular desatado contra la dictadura del General Porfirio Díaz, el desempeño del erario público acusaba otro tipo de zozobra que indudablemente repercutió en el manejo de la empresa estatal y reflejado en la falta de orden en el manejo de los fondos. Al contrario del esquema piramidal anterior, se reedita una idea liberal de igualitarismo de corte político entre los funcionarios a la que no parecía preocupar el tipo de formación ni los niveles de responsabilidad o especialización técnica que la implementación del nuevo sistema de alumbrado implicaba. A guisa de ejemplo se pueden comparar los $\$ 35.00$ que el Juez Primero tenía asignados como sueldo mensual, mientras que un fontanero tuvo asignado emolumentos por $\$ 30.00^{37}$. Destaca en estos años igualmente el hecho de querer impulsar la educación pública básica. Estas y otras cuestiones como la nueva responsabilidad que el personal político posrevolucionario se esforzaba por cumplir, se deja ver en la discusión vertida en un largo escrito de enero de 1920:

Si esta H. Cámara insiste en que el Erario Municipal debe cumplir con el pago al profesorado, y al no contar con numerario para el caso, se verá obligado a soportar una deuda que solo al final del año quizá pueda cubrir [...] estaría muy prudente poner a vuestra consideración que han surgido estas dificultades consecuencia muy natural de que hasta la fecha no se ha conocido en los presupuestos anteriores partida alguna de ingresos que deba cubrir sueldos de profesores [...]

Tlaxcala, Tlax., a 16 de enero de 1920

El Presidente Municipal ${ }^{38}$.

La cita deja ver que entre los principios de modernización de este nuevo gobierno, no solo la electrificación y el alumbrado público, sino la educación popular había pasado de ser una cuestión de civilización a una obligación estatal, una política pública, siguiendo la fórmula que configurase en 1881 el ministro francés de educación Jules Ferry, autor del modelo para la educación pública bajo la fórmula de "universal, gratuita y laica" 39 . Es interesante destacar que la modernización de los servicios públicos urbanos precedió incluso a la atención de la formación ciudadana, prueba de que es más fácil realizar instalaciones materiales que cambios sociales y de las mentalidades.

En otra noticia deja ver también otra actitud novedosa: el deseo de normar al sector eléctrico y los servicios ligados a este artificio tecnológico desde el poder en

Guerra, 1975 y 2003.

37 Tesorería Municipal de Tlaxcala, Estadp-Corte de caja que practicó esta oficina por los Ingresos y Egresos habidos en ellla en el mes de la fecha. México, 31-I-1920. AHET, caja 350, exp. 1.

38 Carta del Alcalde del Municipio de Tlaxcala a la Cámara de diputados del Estado. Tlaxcala, México, 16-I-1920. AHET Sección "Revolución y Régimen Obregonista", Oficios varios del mes de enero de 1920, caja 350, exp. 1, sin número de hoja.

39 Gavari 2005: 415-428. 
proceso de centralización ahora no autocrática sino dentro de las estructuras gubernamentales en formación:

Se ha incurrido en su tramitación en una serie de irregularidades que constituyen una violación a lo que previene la fracción I del artículo 27 Constitucional, pues conforme a este ordenamiento legal, los gobiernos de los Estados están incapacitados para solicitar concesiones o confirmaciones de derechos sobre aguas de propiedad nacional para generación de energía eléctrica para la venta, que es el caso concreto del Gobierno del Estado de Tlaxcala ${ }^{40}$.

¿Qué tipo de nuevo Estado nacional se aprecia en las atribuciones invocadas? Lo que fue una iniciativa de modernización del gobierno tlaxcalteca se veía ahora como una irregularidad para leyes inexistentes al momento de su ejecución y a pesar del entorno ideológico del liberalismo decimonónico, que se juzgaron de manera retroactiva y trataron de aplicar de manera contractual. Esta disputa, evidentemente, no había tenido objeto al momento en el que la acción estatal se vio necesaria en México y el todo el mundo, como veremos más adelante.

El ministerio de Agricultura y Fomento con toda mesura, a través del subsecretario solicitó en 1921 los informes sobre los derechos al uso del agua del río Zahuapan como fuerza hidráulica, lo que indica que si bien se veía como algo anómalo, no era algo grave ni urgente aunque si necesario ${ }^{41}$. Es evidente la poca aprehensión con la que el gobierno tlaxcalteca tomaba estos requerimientos del gobierno central, signo de la debilidad que aún acusaba este, ya que casi tres lustros después no se había solventado la disposición, como muestra la reseña realizada en 1935:

En el expediente existe [...] oficio [...] fechado el 14 de octubre de 1921, en el que se pidió indebidamente al C. Gobernador de aquel Estado que se sirviera informar en que derechos fundaba el aprovechamiento de las aguas del río Zahuapan en producción de fuerza motriz. (Oficio no contestado)

El 22 de noviembre de 1934 se le giró [...] oficio [...] insistiendo en que informara sobre el particular. Tampoco contestó este oficio. El 13 de mayo se le giro [...] nota [...] en la que se le concedió un plazo de 60 días para que legalizara el aprovechamiento ${ }^{42}$.

Parte de la nueva configuración de una administración pública que enfrentaba elementos técnicos se encuentra en los términos de este otro oficio:

Se colige que

Habiéndose procedido al estudio de los expedientes relativos al aprovechamiento de aguas del río Zahuapan en la planta hidroeléctrica llamada Atepatitlán, [sic] se encontró que el Gobierno de ese Estado [...] es el propietario [...] también se procedió al estudio de la situación de derecho de ese propio Gobierno, [...] llegándose a la conclusión de que no tiene capacidad legal para ser el titular del derecho para utilizar las aguas del citado río Zahuapan, declaradas de propiedad nacional por

40 Informe relativo al aprovechamiento como fuerza motríz del río Zahuapan por el Gobierno del Estado de Tlaxcala. Distrito Federal, México. AHA, AS, caja 2400, exp. 34090, hoja. 138.

41 Informe relativo al aprovechamiento como fuerza motríz del río Zahuapan por el Gobierno del Estado de Tlaxcala. Distrito Federal, México. AHA, AS, caja 2400, exp. 34090, hoja 3.

42 Informe relativo a la confirmación del aprovechamiento como fuerza motríz del río Zahuapan al Gobierno del Estado de Tlaxcala. Distrito Federal, México, 12-II-1938. AHA, AS, caja 2400, exp. 34090, hoja 138. 
resolución de fecha 12 de febrero de 1919 [...] en generación de energía eléctrica destinada a la venta, en virtud de que de acuerdo con la fracción I del artículo 27 de la Constitución [...] y con la Ley de Aguas vigente y su reglamento, solo los particulares pueden ser titulares de tal derecho.

[...] siendo necesario que el referido aprovechamiento no se siga efectuando al margen de la ley, en concepto de esta Secretaría existen tres formas conforme a las cuales podría regularizar su situación legal el Gobierno del Estado [...]

a). - La formación de una Sociedad Cooperativa en la que la mayor parte de las acciones quede en poder del Gobierno del Estado de Tlaxcala.

b). - La formación de una Sociedad Anónima en la que, como la anterior, la mayoría de las acciones quede en poder del propio Gobierno.

c). - Que el Ayuntamiento respectivo, como consumidor de energía eléctrica para suministrar los servicios públicos a su cargo, entrase en posesión de la planta hidroeléctrica, pero como parte de esa energía también se destina a servicios particulares, esta forma presenta inconvenientes ${ }^{43}$.

Este reporte, además del formato de pensamiento en voz alta tiene la característica de buscar una solución a una situación de hecho, fórmula de un gobierno que busca centralizar ante los límites de su capacidad de normar. También llama la atención de que manera la ideología liberal seguía en vigor años después de la pacificación del país luego de la lucha por el poder desatada desde mayo de 1911 cuando renunciase súbitamente el autócrata Porfirio Díaz. Evidentemente la participación estatal estructurada en forma de "economía mixta" aún estaba lejos de generalizarse antes de 1936.

El 27 de marzo de 1938 el pasante de ingeniería Carlos Mayoral, con el fin de racionalizar el uso del agua también citó a:

aquellas personas que toman agua para dedicarse al riego de terrenos y que pertenecen al Pueblo de San Esteban [...] en la planta misma propiedad del Estado [...] con el objeto de tratar lo relativo a los derechos que puedan tener sobre el uso de las aguas destinadas al riego [...] de no presentarse [...] se les aplicarán sanciones correspondientes ${ }^{44}$.

José Jorge Flores, arrendatario sin representación legal de la hidroeléctrica, el 15 de febrero de 1938 reiteró una solicitud del 3 de enero de corrección de irregularidades que atribuyó a las operaciones de las fábricas textiles de La Estrella, San Bernabé, Santa Elena, La Trinidad y San Manuel ${ }^{45}$. Esta queja generó un extenso informe que rebasó los objetivos de la inspección realizada que permite entonces conocer los "gastos que se aprovechan, potencias que se generan en las plantas, alturas de caída,

43 Confirmación del aprovechamiento como fuerza motríz del río Zahuapan al Gobierno del Estado de Tlaxcala. Distrito Federal, México. AHA, AS, Caja 2400, exp. 34090, hoja 87.

44 Confirmación del aprovechamiento como fuerza motríz del río Zahuapan al Gobierno del Estado de Tlaxcala. Distrito Federal, México. AHA, AS, Caja 2400, exp. 34090, hoja 26.

45 Comisión al Pasante de Ingeniería, Carlos Mayoral para que se traslade al Estado de Tlaxcala e informe acerca de la forma de resolver la queja del C. José Jorge Flores. Distrito Federal, México, 12-II-1938. AHA, AS, Caja 2400, exp. 34090, hoja 27. 
cambios de turbinas, reparación de canales, funcionamiento de vertedores de demasías, condiciones geológicas de los terrenos, hidrología subterránea, etc ${ }^{46}$ ".

Muy significativa es la actitud del Pasante de Ingeniería Carlos Mayoral, comisionado para realizar la inspección, ya que muestra más a un Estado preocupado por el control burocrático que por el desarrollo industrial. Parecía obsesionado por el fortalecimiento del aparato de gobierno, por lo que en esta línea subraya como necesario:

Verificar la nueva turbina que se instaló en (la fábrica de hilados y tejidos La Trinidad) en relación con el nuevo gasto que consumen y que mediante el cual pudo aumentarse el número de máquinas tejedoras casi el doble de lo que anteriormente tenían.

Cambiar la calificación tanto en pago al erario como en la generación de caballos de fuerza.

Como en el caso anterior se procede a aplicar una multa no solo a esta sino a todas las empresas que lo han hecho, ya que entre ellos mismos han constituido una nueva modalidad para ampliación de canales, hacer reparación a las presas aumentando su altura, cambiar turbinas y aumentar el gasto mediante vasos de almacenamiento sin el correspondiente aviso a esta Dirección ${ }^{47}$.

El nombre de la nueva Secretaría de Fomento y Agricultura parecía solo un anuncio de buenas intenciones o un resabio de la época anterior ya que el reporte del 2 de agosto de 1938 de la Dirección de Geografía, Meteorología e Hidráulica sugería:

Estimándose que de ser necesario se gire una circular a todas las fábricas de la república que utilicen concesiones otorgadas por esta Dirección, previniéndoles de verificar cambios en los trazos originales de sus canales, en las presas, en los vasos de almacenamiento, cambio de turbinas, o en su defecto advertirles del trámite que deben seguir antes de practicar dichas modificaciones o proyecto, pues el caso que siempre alegan ignorancia y se equivocan a su favor, hechos con los cuales posteriormente se traducen en serias irregularidades en el régimen de las aguas, gastos de los ríos y con el consiguiente desorden de los usuarios aguas abajo ${ }^{48}$.

Esta actitud punitiva parecía desdeñar los esfuerzos de reinversión realizados por el conjunto de empresas en una etapa en que el Estado apenas se reconstituía y la sociedad se resarcía de las heridas provocadas por los años de violencia en la trifulca en pos de la conquista del poder central respondía claramente a una coyuntura de crecimiento generalizado de los establecimientos fabriles. ¿Es exagerado hablar de una obsesión? ¿A que se refería entonces cuando concluye su tan acucioso como extenso informe con esta constatación?:

46 Confirmación del aprovechamiento como fuerza motríz del río Zahuapan al Gobierno del Estado de Tlaxcala. Distrito Federal, México. AHA, AS, Caja 2400, exp. 34090, hoja 138.

47 Confirmación del aprovechamiento como fuerza motríz del río Zahuapan al Gobierno del Estado de Tlaxcala. Distrito Federal, México. AHA, AS, Caja 2400, exp. 34090, hoja 129.

48 Confirmación del aprovechamiento como fuerza motríz del río Zahuapan al Gobierno del Estado de Tlaxcala. Distrito Federal, México. AHA, AS, Caja 2400, exp. 34090, hoja 130. 
Ninguno de los vecinos y pequeños propietarios desde la primera hasta la última fábrica están organizados ni mucho menos controlados por los Bancos de Crédito Agrícola y Crédito Ejidal ${ }^{49}$.

Páginas atrás el mismo informe técnico establece el carácter excepcional de esta empresa estatal local cuando anota que:

A pesar de que tiene esta planta dispensa de trámites y demás consideraciones por ser desde hace muchos años propiedad del Gobierno del Estado, planta misma que se encuentra $[\ldots]$ en tramitación [...] su traspaso a otras manos, es conveniente tener dentro de la ley a la parte correspondiente a la concesión de las aguas que se captan utilizando [...] el canal de la misma ${ }^{50}$.

Al enviar los formatos para confirmar derechos al aprovechamiento de las aguas se insistió en la incapacidad legal del Gobierno del Estado en términos de:

La fracción I del artículo 27 Constitucional; pero de acuerdo con lo dispuesto en el decreto presidencial (del) 31 de julio de 1934, la solicitud deberá hacerla el Ayuntamiento de la jurisdicción donde se encuentra instalada la planta [...] y siempre que la energía se emplee exclusivamente en servicios públicos y no para venderla a particulares ${ }^{51}$.

En la cita anterior es perceptible el tratamiento mesurado respecto al uso de aguas consideradas ahora como propiedad de la nación sigue mostrando la especial relación que seguía manteniendo la pequeña entidad en esta nueva etapa de gobiernos "emanados de la revolución", como solían identificarse. Un curioso escrito del 30 de Marzo de 1938 del "Departamento de Aguas y Energía Hidráulica” de la Secretaría de Fomento, citaba a "los usuarios de aguas que las toman en el canal propiedad del Estado con objeto de que presenten sus derechos o concesiones otorgadas por la Secretaria de Agricultura, pues en caso contrario les será cortado la boca-toma" ${ }_{52}$. Nuevamente se percibe el progresivo fortalecimiento del nuevo Estado, pero más aún su especial interés en el control de sectores estratégicos para lo cual la hidroeléctrica estudiada estaba fuera de todos los parámetros.

Hemos recuperado para nuestros argumentos todas estas citas por lo ilustrativas que son, no solo del problema de la operación de la hidroeléctrica del Estado de Tlaxcala, sino también por la manera en que ilustran también sobre el proceso de maduración y fortalecimiento de Estado mexicano, después del periodo de la lucha armada en pos de la conquista del poder de la república. Es el tono de la introducción del escrito hecho por el funcionario de la Secretaría de Agricultura y Fomento encargado del análisis del caso, quien reseñó de esta forma la situación subrayando que:

49 Confirmación del aprovechamiento como fuerza motríz del río Zahuapan al Gobierno del Estado de Tlaxcala. Distrito Federal, México. AHA, AS, Caja 2400, exp. 34090, hoja 135.

50 Confirmación del aprovechamiento como fuerza motríz del río Zahuapan al Gobierno del Estado de Tlaxcala. Distrito Federal, México. AHA, AS, Caja 2400, exp. 34090, hoja 157.

51 Confirmación del aprovechamiento como fuerza motríz del río Zahuapan al Gobierno del Estado de Tlaxcala. Distrito Federal, México. AHA, AS, Caja 2400, exp. 34090, hoja 14.

52 Confirmación del aprovechamiento como fuerza motríz del río Zahuapan al Gobierno del Estado de Tlaxcala. Distrito Federal, México. AHA, AS, Caja 2400, exp. 34090, hoja 54. 
(El uso del agua) del río Zahuapan en generación de energía eléctrica destinada a la venta en la planta hidroeléctrica llamada Apetatitlán, sin que el Gobierno del Estado se haya preocupado hasta la fecha en buscar la forma de legalizar el aprovechamiento [...], no obstante que por oficio de 13 de mayo de 1935 se le dijo al Gobernador de aquel Estado que dentro de un plazo de 60 días y por conducto de la autoridad municipal correspondiente debería legalizar, de acuerdo con la Ley de Aguas, el aprovechamiento que [...] viene disfrutando.

Líneas adelante también se subraya de que manera de daban las relaciones entre las esferas de poder enfrascadas en la contienda:

Hasta la fecha el aprovechamiento que ha venido haciendo el Gobierno de Tlaxcala de las aguas del río Zahuapan [...]en producción de energía eléctrica destinada a la venta, corresponde a una situación [...] consentida por la Secretaría al margen de la ley ${ }^{53}$.

El balance de fuerzas entre las distintas esferas de poder no es cuantificable. Sin embargo, la manera en que se manejaba la clase política desde la capital del país muestra cuanto camino había que recorrer aún para mostrarse como un Estado Federal eficaz capaz de girar determinaciones que fuesen acatadas por una entidad distante menos de 200 kilómetros de la capital del país. Enseguida, en pleno gobierno del General Manuel Ávila Camacho (1940-1946), último presidente militar, ahora era el Gobierno de Tlaxcala el que solicitaba celeridad "respecto del estado en que se encuentra el expediente relacionado con la planta hidroeléctrica de Apetatitlán, Tlax. ${ }^{54}$ Aunque parece la historia de las mil y una noches, vale la pena destacar que el 9 de febrero de 1945, casi al final de este sexenio, se seguía reiterando la solicitud del Gobierno Federal de la documentación probatoria de legalidad, a pesar de que para esa fecha ya se contaban 8 años de existencia del ente estatal "Comisión Federal de Electricidad", creado también por el General Lázaro Cárdenas desde el 14 de agosto de 1937. Todavía era palpable la falta de orden administrativo cuando leemos el oficio correspondiente:

Como la Empresa "Luz y Fuerza de Tlaxcala” propiedad del Gobierno del Estado venía operando con una planta hidroeléctrica [...] se suplica a esa dependencia [...] se sirva acordar se informe si el Gobierno del Estado tiene concesión para el uso de las aguas, así como si esa Secretaría lo autorizó para el traspaso de la concesión $[\ldots]$ y en su caso se envíe copia [...] Ing. Pedro Amigo y Luna ${ }^{55}$.

Este caso sui géneris de empresa energética estatal sugiere muchas lecturas, el Archivo Histórico del Estado de Tlaxcala ofrece enormes posibilidades para el estudio del ejercicio del poder, manifestando de manera transversal su entrecruce con el sector energético. Sin lugar a dudas los resultados aquí presentados contribuyen a

53 Confirmación del aprovechamiento como fuerza motríz del río Zahuapan al Gobierno del Estado de Tlaxcala. Distrito Federal. México. AHA, AS, Caja 2400, exp. 34090, hoja 35.

54 Oficio de la Secretaría General del Gobierno de Tlaxcala al jefe de la oficina de trámites de la Secretaría de Agricultura y Fomento. Distrito Federal, México, 4-IX-1943. AHA, AS, Caja 2400, exp. 34090, hoja 153.

55 Oficio de la Secretaría General del Gobierno de Tlaxcala al jefe de la oficina de trámites de la Secretaría de Agricultura y Fomento. Distrito Federal, México 4-IX-1943. AHA, AS, Caja 2400, exp. 34090, hoja 156. 
investigaciones futuras sobre la relación de esta entidad federativa con el gobierno central en años cruciales. Más aún, demuestran la relación existente entre el proceso de modernización tecnológica que implicó el desarrollo de esta hidroeléctrica con proyectos de modernización de un servicio público primero, y más tarde con la reconfiguración de las políticas públicas, a través de la imbricación de un sector energético clave como lo es el eléctrico con el fortalecimiento de las estructuras de poder.

\section{Conclusión}

Al tratar de responder las preguntas de investigación, se pudo establecer primeramente que dentro de los mecanismos de la iniciativa estatal hubo una combinación de motivaciones mucho más que objetivos puramente económicos. A pesar de sus modesta dimensiones, la hidroeléctrica de Tlaxcala es un caso tan singular como ilustrativo de la historia de la formación de las empresas estatales. Son de destacar no solo la manera tanto precoz como empírica de su desarrollo, sino igualmente la nueva perspectiva que permite para el estudio del surgimiento del estratégico sector de la producción de energía hidroeléctrica en México y posiblemente en otros casos análogos. La información disponible permite además adelantar que fue la primera empresa dedicada a la producción hidroeléctrica totalmente estatal de América Latina $^{56}$. En esta iniciativa gubernamental hubo mecanismos que escaparon al ámbito material económico, motivaciones de corte diríamos emocional, por ejemplo, seguir los procesos de electrificación del país, dentro de la voluntad de modernización que se reflejaba con sus propias características entre las diferentes regiones del país. Ese tipo de obras dentro de la perspectiva modernizadora de la época buscó también ejercer una pedagogía cívica entre la población al acercarse la fecha de celebración del centenario de la emancipación política, tal y como claramente lo expresó Próspero Cahuantzin ante los alcaldes. Aquí encontramos nuevamente la realización de la obra apoyada en argumentos de carácter cívico y no como una manera de legitimación del ejercicio del poder a través de obras de beneficio para la comunidad que se estaba gobernando y representando.

\section{Referencias bibliográficas}

Alba González, Jácome. La economía desgastada. Historia de la producción textil en Tlaxcala. México: Universidad Autónoma de Tlaxcala - Universidad Iberoamericana, 1991.

Araya Ponchet, Carlos. Historia de América en perspectiva latinoamericana. Costa Rica: Editorial Universidad Estatal a Distancia, 2005.

Ayala Mora, Enrique. Historia general de América Latina, vol. VII, Los proyectos nacionales latinoamericanos: sus instrumentos y articulación. 1870-1930. París: Eds. UNESCO, Ed. Trotta, 2008.

Bauman, Zygmunt. Modernidad líquida. México: FCE, 2003.

Bértola, Luis - Ocampo, José Antonio. El Desarrollo Económico de América Latina desde la independencia. México: FCE, 2013.

$56 \quad$ Instituto de Investigaciones, 1997. 
Canudas, Enrique. Las venas de plata en la historia de México: síntesis de historia económica Siglo XIX, vol. I. México: Universidad Autónoma Benito Juárez de Tabasco, 2005.

Cappaso, Gamboa, Álvaro. “Antecedentes históricos del Ferrocarril. Red ferroviaria”. Universidad de las Américas-Puebla, México. S/F, Disponible en: http//:www.catarina.udlap. $\mathrm{mx} / \mathrm{u}$ dl_a/tales/documentos/lic/capasso_g_ag/capitulo1.pdf.

Chávez Peón, Mario Ernesto - San Giacomo Trinidad, Marcela. Tequio nacional o revaloración de la ayuda comunitaria. Ichan Tecolotl, 23 de octubre de 2017. Disponible en: http://ichan.ciesas.edu.mx/puntos-de-encuentro/tequio-nacional-o-de-la-revaloracionde-la-ayuda-comunitaria/.

Connolly, Priscilla. El contratista de don Porfirio. México: El Colegio de Michoacán, UAMAzcapotzalco, FCE. 1997.

Dávila L. de Guevara, Carlos. Empresa e historia en América Latina: un balance historiográfico. Bogotá: Col. Ciencias, 1996.

Díaz Lombardo, Javier. Las obras de Necaxa, Anales de la Asociación de ingenieros de México. Distrito Federal, México: Imp. La Aurora, 1907.

Elster, Jon. Alquimias de la mente: la racionalidad y las emociones. Barcelona: El Roure Editorial - Ediciones Paidós Ibérica, 2002.

Gavari Starke, Elisa. Evolución de la política educativa francesa: de la igualdad a la diversidad. Revista Complutense de Educación, vol. 16, nº 3 (2005), 415-428.

González Molina, Rodolfo Iván. Crisis de los años treinta e impacto en América Latina. México: UNAM, 2011.

González Navarro, Moisés. "Población y sociedad en México, 1900-1970”. Estudios de Historia Moderna y Contemporánea de México, vol. 6, nº 6 (1977), 219-221.

Guerra, F. X. "Politique locale et clientèle au Mexique à la veille de la Révolution". Mélanges de la Casa de Velázquez, nº 11, (1975), 309-332.

— "El soberano y su reino". En Ciudadanía política y formación de las naciones, coordinado por Sabato, Hilda. México: FCE, 1999, 33-61.

- Modernidad e independencias. Ensayos sobre las revoluciones hispánicas. Madrid: Ediciones Encuentro, 2009.

- "De la política antigua a la política moderna: algunas proposiciones". Anuario IEHS, n 18 (2003), 201-212.

Halperín Donghi, Tulio. Historia contemporánea de América Latina. Madrid: Alianza Editorial, 2005.

Hart, John Mason. Imperio y revolución: estadounidenses en México desde la guerra civil. México: Ed. Océano, 2011.

Instituto de Investigaciones Dr. José María Luis Mora. América Latina en la historia económica: boletín de fuentes, no 7-12, Proyecto de Historia Económica, 1997.

Juárez Flores, José Juan. “Agua, agricultura e industria: las transformaciones en el paisaje lacustre de Tlaxcala, 1850-1900”. En El Porfiriato y la revolución mexicana en el centro del país. Miradas desde Querétaro y Tlaxcala, coordinado por Solís, Oliva - Del Llano, Ramón. México: Miguel Ángel Porrúa, Universidad Autónoma de Querétaro, 2011, 25-42.

Ramírez Rancaño, Mario. Próspero Cahuantzi: el gobernador porfirista de Tlaxcala., enero de 1987. Disponible en: www.estudioshistoricos.inah.gob.mx/revistaHistorias/wp.../historias_16_99-116.pdf

Rendón Garcini, Ricardo. El prosperato: el juego de equilibrios de un gobierno estatal (Tlaxcala de 1885 a 1911). México: Siglo XXI Editores, 1993.

Secretaría de Hacienda y Crédito Público. SHCP, 1880. 